\title{
Editorial
}

\section{The history of revenue and pricing management -15 years and more}

\author{
lan Yeoman \\ School of Management, Victoria University of Wellington, Wellington, New Zealand. \\ E-mail: ian.yeoman@vuw.ac.nz
}

\begin{abstract}
Seventeen articles celebrate the 15 years of publication for the Journal of Revenue and Pricing Management. Chronologically mapping out the history of Revenue Management (RM) from the beginnings of post-deregulation in the Airline industry, the practices of RM, the evolution into the hotel and other industries, the development of theories and new applications in a multi-disciplinary field, the impact of technology, and the Internet and movement towards pricings. The special issue, which includes contributions from leading academics, vendors, practitioners and researchers combined represents the history of RM.
\end{abstract}

Journal of Revenue and Pricing Management (2016) 15, 185-196. doi:10.1057/rpm.2016.36

Keywords: revenue management; pricing; history

\section{INCEPTION}

Launching a new journal in 2002 post-9/11, when the main readers were members of the airline industry, may not have seemed like a good idea at the time. I co-chaired AGIFORS Revenue Management (RM) conference in Athens in 2001, post-9/11 and the conference was void of any of the main carriers, in fact the largest delegation to the conference was from British West Indies Airways. A sense of doom and gloom prevailed. Not the time to launch or gather interest in a new journal. I remember the Publishing Editor Daryn Moody, of Henry Stewart saying at the time, if we can increase the subscriptions from 4 to 10 in the next few weeks, we will publish the first issue!' Well we did achieve that, with 20 institutional subscriptions in the first year.

The publishers had confidence, so we published. Since then we have increased the base of the journal to more than 20 to become recognized as the Journal of Revenue Management. This has been a journey of a team, a range of people who have championed and supported the journal. From Una McMahon-Beattie as Deputy Editor to Larry Weatherford's continued contributions through AGIFORS. Sheryl Kimes who contributed significantly on hotel and restaurant $\mathrm{RM}$ channelling her $\mathrm{PhD}$ students to submit to the journal. Warren Lieberman using his influence with INFORMS Revenue and Pricing Management section to develop a partnership with the section. The continued support from industry, in particular Ben Vinod of Sabre who has presented a series of thought pieces over the last 15 years which can only be described as cutting edge. Stefan Poelt of Lufthansa Systems who is always there. Mark Shafer from Walt Disney who has always encouraged his team to write for the journal, therefore bridging practice with theory across a diversity of applications. Steven Pinchuk of IBM, who has championed the journal with passion over the last 15 years. A special mention to Peter 
Belobaba at MIT as the founding co-editor, whose reputation created this journal. Today, the journal is published by the world's leading independent academic publisher Palgrave Macmillan.

\section{THE OPENING ADDRESS}

It is with pleasure that the opening article of this special issue is written by founding editorial board member Paul Rose. When I first floated the idea of the journal. Paul, then of British Airways (BA) was so enthusiastic, he flew up to see me at Napier University in Edinburgh to discuss the possibilities that he and BA could contribute. His article reflects on Paul Roses' 35 years of experience in Airline RM focusing on the development and changes. His personal insight about BA should be commended. A lifetime in Airline Revenue Management tells the story of how in the 1970s RM consisted of very simple basic inventory controls based on gut feeling and hope, with few prices to manage and no such thing as brands. In the 1980's deregulation in the United States drove multiple fare offerings worldwide requiring more sophisticated inventory controls of up to 26 selling classes. British Airways' RS13 inventory control system was perhaps leading edge in this area with colour coded triggers and the addition of point of sale controls too. The stories of the lack of faith in technology and forecasting tools as the Low Cost Carrier emerged. This is the one article in the special issues that captures the history through personal insight.

\section{THE LAST 15 YEARS...}

I asked members of the editorial board to reflect upon the last 15 years, and these were there thoughts:

This special issue provides us with an opportunity to celebrate 15 amazing years of the Journal of Revenue and Pricing Management. We can truly say that we have been on a fantastic journey which has resulted in the development of a dedicated community of revenue and pricing management academics and industry professionals. This journal has allowed us to showcase world class theory and practice which has played a significant role in supporting businesses and organisations in achieving their goals.

Una McMahon-Beattie, Department of Hospitality and Tourism Management, Ulster University, UK

The journal has certainly filled a gap as a means to promote the advancement and communication of pricing and revenue management principles and theory over the past 15 years. As RM principles spread to new industries and pricing becomes a core and strategic function in more and more companies, the journal has provided practitioners and academics with a platform to spread best practices and new approaches to pricing.

Göran Skugge, Senior Partner, PriceGain, Sweden

The best way to keep up-to-date with advancements in the field, both theory and practice.

Emmanuel Carrier, Operations Research Consultant, Delta Airlines, USA

The best research related to hospitality management and revenue management is published in the Journal of Revenue \& Pricing Management. I use the articles extensively in my revenue management classes.

Basak Denizci Guillet, Associate Professor of Financial and Revenue Management School of Hotel and Tourism Management, The Hong Kong Polytechnic University, Hong Kong

As a founding member of the Editorial Board I remember when RM was still in its early stages as a Management Science. I was chairing RM conferences around the world and saw the hunger practitioners 
had for quality RM and pricing information. Conferences were a magical place where people gathered who shared these new thoughts. The Journal quickly became THE trusted source where academics and practitioners joined to learn and plan the art of their craft. Now the Journal is the only place with this constant flow of quality materials. Long before new ideas are implemented they are presented in the Journal. Now RM and pricing are mainstream functions in companies and the need for the Journal has never been greater.

Steve Pinchuk, Analytics, Customer Intelligence \& Profit Optimization, IBM, USA

The Journal of Revenue and Pricing Management is the only journal of its kind, dedicated to the science and practice of pricing and revenue management. Since its inception, Ian Yeoman has gone the extra mile with his dedication and focus on delivering a journal with a range of rich diverse topics dedicated to educating practitioners and providing transparency to current trends and advances in this important subject.

Ben Vinod, Senior Vice President \& Chief Scientist, Sabre Holdings, USA

The journal has filled a gap by delivering a unique focus on the world of RM to both practitioners and academics alike, which given the demise of many of the high quality RM conferences held in past years makes it even more essential now than 15 years ago. In recent years with the advent of Low Cost Carrierss and a faster turnover of airline resources in full service airlines the expertise once enjoyed has somewhat diminished at many airlines, so the journal can help plug that lack of knowledge and enhance new joiners to RM understanding of the subject matter.

Paul Rose, Managing Director, Paul Rose Revenue Management Ltd, UK
The most important development of the first 30 years of Revenue Management history has been the birth and growth of the body of concepts and the community of practice - the backbone of RM theory. The Journal of Revenue and Pricing Management has made a very significant contribution as a central repository and focal point of this knowledge creation. Bravo!

Bill Brunger Senior Vice President Network, Continental Airlines (ret.) and CEO of PODS Research LLC, USA

Revenue management was born in the airlines, and the concepts of inventory management and price optimization has spread to new industries, such as retail and energy. The widespread growth would not have been possible without a forum such as the Journal of Revenue $\mathcal{E}$ Pricing Management, and the active participation of an exchange of information among both practitioners and academicians in the Journal.

John Quillinan, Senior Managing Consultant, IBM Analytics, USA

Congratulations! JRPM have contributed to many insights of revenue management systems in the last 15 years, be it theoretical or applied. From algorithms to best practices, analytical models to pricing strategies, JRPM has informed many of its readers. However much still remains to be explored and examined as the business environment becomes ever so competitive with the digital age.

Nick Yip, Lecturer in Marketing, University of East Anglia, UK

JRPM has provided a perfect balance of industry relevant and academically oriented papers within RM, and established itself as a premier outlet for thought leadership. The journal is up-and-coming quality journal that is relevant for RM. It 
will be interesting to see how it tracks in attracting good papers (and hence citations) and increase recognition in terms of impact factor and relevance for promotion and tenure cases.

Fredrik Odegaard. Associate Professor of Management Sciences, Ivey Business School, Canada

The revenue management discipline has brought about the birth in the application of decision science to solve a wide array of business problems across all industries. By leveraging the Journal of Revenue and Pricing Management you are able to gain essential insights on how to tackle some of these most difficult business problems and leverage these learning's across industries.

Mark Shafer, Senior Vice President Revenue and Profit Management at Walt Disney World, USA

This has been a wonderful experience - to take a chance on a brand new journal back in 2001 in the burgeoning field of Revenue Management. And wow, what joy to see that the journal actually made it and is now flourishing! We've gone from 4 issues per year to 6 per year and we have organized into one journal all the research that both practitioners and academics alike want to see. My warmest congratulations to the Editor and the Publisher!

Larry Weatherford, Professor and Scarlett Endowed Chair at University of Wyoming, USA

For 15 years, we have had the pleasure to read Journal of Revenue and Pricing Management articles, and to teach in the Master program at the University of Angers. Both are definitely important for all of us: industry need revenue managers, revenue managers need education program, and we all need a place where to share ideas, communicate, develop methods and concepts, bring together academics' and practitioners' experiences. Journal of Revenue \& Pricing Management is the place where we all joined in the past 15 years! And we will keep on doing so in the next 15 years!

Patrick Legohérel, Professor, University of Angers, France

The Journal has become a great source of ideas ranging from research topics to dayto-day relevant challenges and opportunities for practitioners. I am pleased to see that the Journal has widened its spectrum by balancing the content between these areas. The broader content made the Journal suitable for a wider range of readers and enables building bridges between theory and practise. I have always encouraged people to contribute to the Journal by writing a paper. Learning is a matter of give and take and the Journal has proven to be an excellent platform for sharing knowledge and experience.

Dieter Westermann, Senior Vice President Revenue Management Strategy \& Solutions, Pricing \& Revenue Management, Qatar Airways, Qatar

The Journal of Revenue and Pricing Management has become the leading journal devoted to a wide range of topics related to pricing and revenue management, both theoretical and practical. Its strength lies in the breadth of coverage of RM applications in many different industries and a highly interdisciplinary approach that most traditional journals cannot deliver.

Peter P. Belobaba, Principal Research Scientist, Department of Aeronautics and Astronautics, Massachusetts Institute of Technology, USA

The Journal of Revenue and Pricing Management created a unique opportunity for practitioners to present their ideas and thoughts to a wider audience of peers 
and academics. It has bridged a gap between academia and the industry.

Karl Isler, Senior Director and Head of Revenue Management Strategy and Operational Research, Swiss International Air Lines Ltd, Switzerland

During the past 15 years, the field of revenue and pricing management has opened up to a much wider range of industries than aviation and transport, and this has been one of the triumphs of the Journal of Revenue and Pricing Management.

Christine Currie, Associate Professor of Operational Research at University of Southampton, UK

Even while research questions and practical challenges change with the advent of a more connected digital economy and new business models, this journal have always served to remind me that 'payment is applause' and that pricing remains one of the most crucial interaction with customers that drive profits and the economy and is constantly in need of innovative ways in thinking about it.

Irene Ng, Director, International Institute of Product and Service Innovation, Professor of Marketing and Service Systems, University of Warwick, UK

Being both a contributor and a consumer of information provided by the journal it has meant a lot to me. It has provided venue for my own publications and thus helped in my career. As importantly. One aspect that I find very valuable is that you can read about things, especially related to the practice of RM and Pricing, that would be hard to find anywhere else. I think that the category of 'practice papers' is very valuable since it allows disseminating valuable observations of authors without making them go through unnecessarily high threshold of technical rigor. In this way important ideas and intuitions can be be spread out and discussed faster and more efficiently. Among RM practitioners the journal has become a sort of a standard, and people cite and quote articles.

Darius Walczak, Principal Research Scientist, PROS Inc., USA

My first encounter with the journal was in 2005 while writing a paper on overbookings. It inspired me to delve deeper into revenue management issues and to introduce the first Revenue Management module in a Bulgarian higher education institution in 2009. For the future I would like to see more articles dealing with the mathematical modelling of revenue management problems and cases on the use of artificial intelligence in revenue management.

Stanislav Ivanov, Vice Rector for Academic Affairs and Research, Varna University of Management, Bulgaria

As a premier journal in its field the Journal of Revenue \& Pricing Management gives practitioners and academics the opportunity to share thoughts and findings which are of huge practical importance while operating at the forefront of knowledge discovery and scientific progress. The journal's interdisciplinary and multi-industry perspective has become a key source for all who seek to advance their knowledge on the optimal revenue management of perishable assets, especially the thinking of tomorrow's practical and intellectual challenges.

Jean-Pierre I. van der Rest, Associate Professor, Department of Business Studies, Institute of Tax Law and Economics, Leiden Law School, Leiden University, The Netherlands

\section{THE HISTORY OF RM}

The history of RM is recognized in the contribution from Ben Vinod of Sabre 
Technologies in the article Evolution of Yield Management in Travel. The article starts off with the recognition that Yield Management came into existence on a significant scale a few years after the deregulation of the US airline industry in 1978 under the administration of Jimmy Carter. The deregulation Act of 1978 was a dramatic event in US economic policy, and it dismantled a comprehensive system of government controls. Before deregulation, airlines operated in a tightly regulated environment; regulated by governments and self-regulated through organizations such as the Civil Aeronautics Board and the International Air Transport Association. The article is a comprehensive chronological account of RM right upto today.

The next series of articles look at the milestones or significant tipping points that have brought RM as a core management function in Airline industry. Larry Weatherford's first article The History of Forecasting Models in Revenue Management, basically states that without developments in forecasting technologies and algorithms there would be no RM today. Since the early days of the practice of RM, no one can doubt the importance of the forecasting engine that provides the input of unconstrained demand to the more mathematically sophisticated optimization engine or that provides the input of the no-show rate forecast to the overbooking engine. Indeed, forecasting is an important part of any business. Larry's second article, The History of Unconstraining Models in Revenue Management provides the input of unconstrained demand to the more mathematically sophisticated optimization engine. Indeed, forecasting and planning is an important part of any business. Together, these articles represent the catalysts of Revenue Management today.

The combination of these two elements represent taking RM to the next level. This enabled the development of optimization models in airline RM systems have been evolving from single flight leg to network revenue maximization to marginal revenue optimization for less restricted fare structures. Peter Belobaba is seen as the founding father of RM who brought the topic into a new era. Optimization Models in RM Systems: Optimality Versus Revenue Gains reviews the most common optimization approaches that have been widely implemented in airline RM systems, with a focus on how the mismatch between model assumptions and reality can affect achievable revenue performance. Simulation findings from the Passenger OriginDestination Simulator are used to illustrate how robustness and revenue gains, as opposed to theoretical optimality, have driven the widespread adoption of practical optimization models in RM systems.

Stefan Poelt of Lufthansa Systems in the History of Revenue Management - From Leg to OED notes the rise O\&D (origin and destination) control is down to the first computer reservation systems that automated the former manual accept/reject decisions of booking requests and controlled the number of bookings by booking limits per leg and booking class. The main disadvantage of this leg-type control was the inability to distinguish between local and connecting passengers. The advances in computer power and distribution capabilities (seamless polling) in the 90s enabled forecasting, optimization and availability control at O\&D level. This enhancement allowed better evaluation of booking requests and closer integration of RM and pricing. Bill Brunger, retired Senior Vice President of Continental Airlines writes about four operational difficulties of working with RM in Inventing RM: How it Felt to Write a Revenue Management (RM) System Without Precedents the Scene. First of all, weak theory. Bill knew about Belobaba's (1986) Expected Marginal Seat Revenue (EMSR) thesis but had never seen a copy. Second, primitive technology and tools meant Bill handwrote Continental's first system RM system in IBM's APL language. APL required a key board with Greek letters - Continental owned two such machines, neither of which could be used on an airplane, and Continental had only one employee (me!) who 'spoke' APL. Third, immature airline processes where not in place. RM pioneers had to convince Senior 
Management and, as importantly, Field Sales that the discount inventory allocation levels would result in higher revenues and therefore should be respected. Finally, corporations are always infected with inertia - airlines had existed without RM, why did they need it now? RM seemed risky. RM required changes to processes and procedures. RM demanded a centralized control of inventory in an industry well-known for hierarchical structure and organizational 'fiefdoms'.

\section{FROM AIRLINES TO HOTELS: THE BEGINNINGS OF DIVERSIFICATION}

We think of RM and we think Airlines, but one of the first industries to adopt RM was the hotel industry. Sheryl Kimes is the Professor of Hotel RM and has pioneered the subject at the Cornell Hotel School. In the article The Evolution of Hotel Revenue Management Kimes discusses the history of hotel RM and trace its evolution over the past 25 years. The most important change in hotel RM has been its evolution from a tactical inventory management approach to a more strategic marketing approach. For example, back in the early years of hotel RM, rates were assumed as a given that the inventory management system opened and closed. Hotels did not necessarily look at how to develop other market segments to fill slow demand periods or for that matter, even try to understand if the prices that were being offered were optimal. How things have changed! While the inventory management aspects of RM are obviously still there, RM has become a much richer and more strategic field of business. This is demonstrated in a number of ways including the organization of the RM function, the role that pricing now plays, the application of RM principles to other parts of the hotel and the change in how RM performance is measured.

Inspired by the success of yield management in the airline industry, the hotel industry started to apply RM in the late 1980s, because its products shared many similar characteristics such as perishability, fixed capacity and the need for segmentation based on customers' levels of price sensitivity. Stan Josephi and his Dutch colleagues write in Hotel Revenue Management: Then, Now and Tomorrow that as hotel RM is typically performed from a purely operational and tactical level, its definition has remained virtually unchanged and still pivots around the 'art and science' of allocating capacity and prices to customers to optimize revenues. Natalie Hayes from Sheffield Hallam University writes in the article The Evolution of Competitor Data Collection in the Hotel Industry and its Application to Revenue Management and Pricing explores the move towards the collection and processing of hotel competitor set data since the late 1970s. It identifies a shift from using internal metrics to measure the revenue-generating capabilities of a hotel, such as performance against budget, to the use of large amounts of detailed competitor set data processed for hotels by third parties. It analyses the impacts of these changes on the way pricing and revenue decisions are made and suggests that the modern manager may have become over focussed on competitor data, potentially diverting the focus from hospitalityspecific success factors such as customer service.

\section{EVOLUTIONARY}

As RM becomes the norm in the hotel industry, theory and ideas of how to use RM evolves. Breffni Noone (a PhD student under Professor Kimes at the Cornell Hotel School and now an Associate Professor at Pennsylvania State University) argues in Pricing for Hotel Revenue Management: Evolution in an Era of Price Transparency that the recession of the early 2000s, the emergence of online booking channels and the price transparency afforded by the Internet, coupled with challenges to the basic assumptions underlying traditional RM systems, have fuelled significant change in how the hotel RM problem is approached. Some customers book but never show up. So, how do managers manage no-shows in industries where inventory 
is time dependent that is, bedrooms, airline seats and so on. ChihChien Chen of the University of Nevada takes us into the area of overbooking and cancellation policies in the article Cancellation Policies in the Hotel, Airline and Restaurant Industries. Littlewood's (2006) Rule and EMSR (Belobaba, 1987) maximize revenue through the allocation of various fares quoted for different levels of customers' willingness-to-pay. Both assume no cancellations or no-shows, an unrealistic assumption. The airline industry, by contrast, has been consistently stringent about such policies. Therefore, the purpose of this article is to provide an overview of cancellation policies across airline, hotel and restaurant industries demonstrating the origin of cancellation policies, mathematics modelling of cancellation policies, how major changes have occurred and their consequent impacts that currently allow for cancellation sophistications in industries. Timothy Webb of Virginia Polytechnic Institute, in his article From Travel Agents to OTAs: How the Evolution of Consumer Booking Behaviour has Affected Revenue Management. Travel booking behaviour has changed substantially over the past two decades. The traditional approach of utilizing travel agents and booking ahead has evolved into a fast-paced, last-minute booking environment. This evolution has had substantial effects on RM in the areas of forecasting, pricing and online travel agency inventory allocations. These changes have made understanding the consumer booking process a necessary requirement for success.

\section{HOW BIG DATA AND INTERNET CHANGED THINGS}

The introduction of World Wide Web browsers (Mosaic and Netscape) in the mid 1990s saw the emergence of e-commerce, and around the same time with the development of tracking cookies online merchants were also able to track and store data about visitor's activities on their site as well as elsewhere on the web. Within a short period of time, companies such as Amazon started using data gathering and collaborative filtering techniques based on visitors past activities to offer personalized shopping suggestions (Turow et al, 2015). Thus, the arrival of the Internet and Google has brought about the era of one to one segmentation as Big Data becomes the norm. Big data is a term for data sets that are so large or complex that traditional data processing applications are inadequate. The term often refers simply to the use of predictive analytics or certain other advanced methods to extract value from data, and seldom to a particular size of data set. Accuracy in big data may lead to more confident decisionmaking, and better decisions can result in greater operational efficiency, cost reduction and reduced risk thus being able to identify the customer who is willing to pay the right price for the right capacity at the right time.

The availability of data is the central idea taken up by RM pioneer Warren Lieberman of Veritec Solutions, who writes in the article The Evolution of Market Segmentation in Revenue Management and Dynamic Pricing Market that segmentation techniques that have played an extraordinarily important role in successful RM programs. For example, purchase fences allowed companies to sell a single product at multiple prices, simultaneously, to customers that selfselected into different customer segments, based on willingness-to-pay. As RM, expanded to more industries, new approaches to market segmentation became possible. The financial benefits associated with successful implementations have been extraordinary. The article discusses how market segmentation techniques have evolved in support of RM and dynamic pricing practices and what companies and customers may be able to look forward to in the future. Dax Cross of Revenue Analytics takes this concept further in the article $A$ History of Revenue Management and the Advent of NextGeneration $R M$, arguing that arrival of price transparency and dynamic pricing in the travel and hospitality industries - fuelled by the rise of the Internet and a dynamic hyper-informed consumer - demands a fresh approach to traditional RM. This article explores how these 
disruptive changes resulted in Pricing and Revenue Management innovations that led to the rapid expansion of the discipline into industries such as automotive, cruise lines and retail.

Dax records that the discipline of RM rose to prominence in the 1980s and 1990s by offering and optimizing differentially priced, fenced products to various market segments to drive organic revenue growth. In the early days of the discipline, airlines were responding to the disruptive event of deregulation, which led to fierce competition and reduced profits. Airlines developed initial RM capabilities, and the results were substantial, giving rise to in-house RM teams and rapid development of technology to deliver innovative strategies across travel and hospitality. Then came the Internet and the era of price transparency, the seismic shift that shook the foundations of yield management and sent shockwaves through the travel and hospitality industries. This disruptive event fuelled by the exponential growth of the Internet and a win for consumers who could now easily and quickly compare prices for airline seats, hotel rooms, cruise prices and so on initially caused chaos in the C-suite. Consumers, for the first time, were empowered to almost instantly assess and value products before buying them. With price shopping and comparison across competitors facilitated by technology, companies began to focus more attention on pricing and made more frequent price changes. The result was fierce and dynamic price competition. The decline in hotel demand in the recession of the early 2000 s, coupled with the rise of Internet booking channels and price transparency, posed challenges to the long-time RM calculus and required a fresh strategy for hotels. Now the focus was not on inventory allocation, it would be more impactful to add focus to pricing.

\section{THE EMERGENCE OF CONSUMER POWER}

Una McMahon-Beattie at Ulster University has chalked up a reputation as the expert in
RM and the customer, her article titled Revenue Management, Pricing and the Consumer is an example of the evolution of the topic as more than operational research and mathematical algorithms towards a holistic approach. If the primary aim of RM is selling the right product/service to the right customer, at the right time, for the right price, in order to generate revenue from perishable capacity, then an understanding of consumers and their behaviour is critical to its effective development and implementation. Indeed, this has become even more important in recent years as a result of the global economic strains of recession and exchange rate changes that have seen the rise of the 'strategic customer' empowered by smartphone technology and the emergence of price comparison/aggregator Websites, customers continue to seek absolute value and the best price available. Simply put, the dynamics of supplier pricing are more visible to consumers and, in response, they are adapting their buying behaviour. As such understanding consumer behaviour has quite rightly become more important in RM. If there is an absence of trust and a lack of perceived fairness, it has been argued that consumers are unlikely to purchase, and that there is an adverse effect on customer satisfaction, word-of-mouth intentions and loyalty. However, the role of trust is little understood. So further work needs to be done in relation to when the customers choose to buy a particular product/service in response to a supplier's dynamic pricing practices. In addition, the impact of competitor behaviour on RM models still requires further research with many models treating rival firms behaviour as fixed.

\section{ITS PRICING NOT RM}

A significant development for the Journal of Revenue and Pricing Management in the last couple of years has being the promotion of Pricing content, given the shifts in consumer behaviour, big data, technology and the 
Internet. The appointment of Stephan Liozu as Associate Editor Pricing was a significant step in that development (along with Andreas Hinterhuber). Stefan Liozu's article The Evolution and Future of Pricing Capabilities demonstrates how business faced with increased competition and pricing complexity, more attention has been paid to pricing capabilities. Grounded in resource-based view and capability-based view of the firm, pricing capabilities have moved over time from a nonexisting concept to an emerging theory rich in both qualitative and quantitative research articles. From the mid-2000 to today, pricing scholars have demonstrated the need to pay greater attention towards pricing capabilities to increase competitive advantage and firm performance. This article examines the evolution of the concept of pricing capabilities over time, the current state of pricing capabilities theory and the future ahead for this emerging field.

\section{THE NEXT 15 YEARS}

So, what about the next 15 years, I asked Editorial Board members for their thoughts and these are the replies;

Over the next 15 years, I would expect the journal to continue to show how revenue management can be applied in diverse application areas, as well as adapting tools from data science to improve the implementation of revenue management techniques.

Christine Currie, Associate Professor of Operational Research at University of Southampton, UK

I think the 30th anniversary issue should consider pricing in a broader sense in the way that there are new types of transactions in the connected digital economy, e.g., in-app pricing for digital services, i.e., transacting at new boundaries that call on new pricing and revenue models, new conceptualizations and ways to use digital medium for such pricing mechanisms.

Irene $\mathrm{Ng}$, Director, International Institute of Product and Service Innovation, Professor of Marketing and Service Systems, University of Warwick, UK

Over the next 15 years I think the JRPM will represent that RM will revert back to more basic and simple models. Currently the evolution of the models and algorithms is to make them more and more complicated and more and more encompassing. I think once 'RM steady state' in a particular industry of business kicks then the required models and framework will be very simple. We might see pricing models only incorporating a single factor, or perhaps static capacity levels employed. We will have simple but robust models.

Fredrik Odegaard. Associate Professor of Management Sciences, at Ivey Business School, Canada

It is to the merit of the Journal of Revenue and Pricing Management to provide a forum where the disciplines of pricing and operations management intersect to provide rigorous and actionable insights. Emerging trends: an increase in studies that examine the application of revenue management outside traditional industries. I would also expect that we will gradually include a third foundation: psychology. Understanding how consumers react to alternative prices or pricing models and examining the psychological antecedents of alternative pricing strategies at the level of the decision makers will all make for fascinating studies able to positively shape research and practice.

Dr Andreas Hinterhuber at Hinterhuber \& Partners, Austria

My only desire for the next 15 years is more case studies and content delivered by 
practitioners from all industries highlighting the day-to-day problems they encounter in the real world to bring the journal's content even more to life.

Paul Rose, Managing Director, Paul Rose Revenue Management Ltd, UK

I believe that over the next 15 years personalization, dynamic packaging and real-time distribution will add additional content to the Journal. These topics are about to change airline revenue management and pricing and I am looking forward to exciting papers being published in the future.

Dieter Westermann, Senior Vice President Revenue Management Strategy \& Solutions, Pricing \& Revenue Management, Qatar Airways, Qatar

My wish for the next 15 years is more eclectic and behavioral work in RM without neglecting consistency in thinking, grounded in the optimization opportunities that the online world and technology will provide us, without losing track of social responsibility, sustainability and social justice.

Jean-Pierre I. van der Rest, Associate Professor, Department of Business Studies, Institute of Tax Law and Economics, Leiden Law School, Leiden University, The Netherlands

Being a practitioner of pricing in many different industries, I see an opportunity for the journal over the next 15 years to serve as a vehicle for communicating state-ofthe-art pricing techniques in industries that don't have the RM and pricing history of the travel and transportation industries.

Göran Skugge, Senior Partner, PriceGain, Sweden

\section{CONCLUDING THOUGHTS}

The first attempt at value pricing was American Airlines initiative in April 1992 to transition to a simplified fare structure that had grown in complexity since airline deregulation. Instead of selling seats at several prices, American offered only four types of fares - first class, regular coach and two discount coach fares which had 7-day and 21-day advance purchase restrictions, respectively. RM (or Yield Management in those early days) was classified as a series of characteristics coined by Kimes (1997) as necessary conditions as fixed capacity, high-fixed costs, low variable costs, time-varied demand with similarity of inventory units. Necessary ingredients were market segmentation, historical demand, pricing knowledge, overbooking policy and information systems using rate controls, availability controls or allocation approaches. These control approaches were the foundations of Littlewood's (2006) Rule and EMSR (Belobaba, 1987). Today, the evolution has moved beyond control and allocation to distribution systems, origin and destination, dynamic pricing and total approach to RM that is multi-disciplinary not just operations research. Price analytics enables better understanding of elasticity and behavioural economics. The past may not represent the future, but the articles presented in this special issue are a documented evolution.

The Journal of Revenue and Pricing Management serves as a bridge between practice and theory in order to advance the field through dissemination and publication of leading articles for the benefit of industry and the wider community. A strong emphasis is placed on the utility value of research in which application is demonstrated. The journal has grown from four issues per year in 2002 to six per year in 2016. The number of articles has exponentially grown, balancing academic research and practical value. The whole journey has been a team effort for which there are so many people to thank.

I hope the journal has brought you understanding through insight and value with articles over the last 15 years emphasizing meaningful answers to problems whether cutting edge science or real solutions. So, let the journey continue. 


\section{REFERENCES}

Belobaba, P.P. (1987) Air Travel Demand and Airline Seat Inventory Management. Flight Transportation Laboratory. Cambridge: MIT. Kimes, S. (1997) Yield management: An overview. In: I. Yeoman and A. Ingold (eds.) Yield Management: Strategies for the Services Industries. Chapter 1. London: Cassell, pp. 3-11.
Littlewood, K. (2006) Forecasting and control of passenger bookings. Journal of Revenue and Pricing Management 4(2): 111-123. Turow, J., McGuigan, L. and Maris, E.R. (2015) Making data mining a natural part of life: Physical retailing, customer surveillance and the 21st century social imaginary. European Journal of Cultural Studies 18(4-5): 464-478. 